\title{
EFEITOS DO CRESCIMENTO ECONÔMICO SOBRE OS ESTADOS BRASILEIROS (1992-2006)
}

\author{
Rosa Lívia Gonçalves Montenegro * \\ Thiago Henrique Carneiro Rios Lopes ${ }^{\dagger}$ \\ Luiz Carlos de Santana Ribeiro ${ }^{\ddagger}$ \\ Ítalo SpINelli da Cruz $\S$ \\ Camilla Petrelli Corrêa de Almeida ${ }^{\text {II }}$
}

\begin{abstract}
Resumo
A economia brasileira foi marcada por importantes mudanças ao longo da década de 1990 e início dos anos 2000. O objetivo deste artigo é analisar o processo de crescimento econômico dos 27 estados brasileiros no período sob análise. Para tanto, utiliza-se a metodologia da Análise Exploratória de Dados Espaciais (AEDE) e modelos de regressão espacial com dados em painel. Os resultados mostram que alguns efeitos para o crescimento econômico brasileiro foram importantes como os anos de estudo e, em menor grau, os gastos do governo e a taxa de fecundidade. Ademais, a principal conclusão do trabalho foi que a taxa de crescimento dos estados brasileiros não é significativamente afetada pelo crescimento dos seus estados vizinhos.
\end{abstract}

Palavras-chave: Crescimento econômico; Estados brasileiros; Modelos em painel de dados com dependência espacial

\begin{abstract}
The Brazilian economy were marked by deep changes during 1990's and early 2000 's. The objective of this paper is analyze the economic growth process of the 27 Brazilian states in the period under analysis. In this regard, we use the Exploratory Spatial Data Analysis (ESDA) and spatial regression models with panel data. The results shows that some effects for the Brazilian economic growth were important such as years of study and, with less intensity, government expenditures and fertility rate. Furthermore, the main conclusion was that the Brazilian states' economic growth rate is not significantly affected by the growth of its neighboring states.
\end{abstract}

Keywords: Economic growth; Brazilian states; Panel data model with spatial dependence

JEL classification: C31, C33, O47, R11.

DOI: http://dx.doi .org/10.1590/1413-8050/ea398

\footnotetext{
*CEDEPLAR/UFMG. E-mail: rosalivia@cedeplar.ufmg.br

† CEDEPLAR/UFMG. E-mail: thiagohenriquerios@gmail.com

‡ CEDEPLAR/UFMG. E-mail: ribeiro.luiz84@gmail.com

$\S$ NUPEC/UFS. E-mail: italo.spinelli@gmail.com

II CEDEPLAR/UFMG. E-mail: camillapetrelli@cedeplar.ufmg.br
} 


\section{Introdução}

A trajetória recente da economia brasileira é caracterizada por grandes transições econômicas. Para o período analisado neste estudo, que abrange os anos entre 1992 a 2006, é oportuno mencionar alguns aspectos relevantes. Entre os anos de 1990 a 1994, iniciaram-se os processos de privatização, abertura comercial e financeira, além da estabilização monetária com o surgimento do Plano Real. No período entre 1995 e 2002, se consolida o processo das reformas econômicas e da política de controle inflacionário, além da adoção do novo regime de política macroeconômica a partir de 1999. No triênio 20032006, verificou-se um relativo processo de crescimento econômico, com níveis mais elevados de investimento e aumento do emprego.

O desenvolvimento formal dos modelos de crescimento econômico ocorre somente no final dos anos 1930 e meados da década de 1940. Dentre as vertentes mais importantes, três delas merecem destaque. A primeira diz respeito aos modelos de tradição keynesiana por meio dos estudos de Harrod (1939) e Domar (1946). Na segunda vertente evidencia-se o modelo neoclássico de crescimento exógeno elaborado por Solow (1956). Por fim, destacam-se os modelos de crescimento endógeno inspirados pelos trabalhos de Romer (1986) e Lucas (1988). Romer (1990) endogeniza o progresso tecnológico que é guiado por pesquisas e desenvolvimento nos países avançados. Outro trabalho relevante na literatura de crescimento foi realizado por Mankiw et al. (1992). Esses autores propuseram uma ampliação do modelo de Solow (1956) a partir da inclusão de uma variável que representasse a acumulação de capital humano. Vale salientar que a preocupação de que fatores associados ao capital humano afetam o crescimento teve origem com Lucas (1988) com inspiração no trabalho de Becker (1964).

Os estudos mais recentes sobre crescimento econômico têm se preocupado em considerar o espaço como elemento de análise. O surgimento da teoria da Nova Geografia Econômica, Fujita et al. (1999) associado ao aprimoramento da modelagem de econometria espacial, tem permitido a identificação de um conjunto de variáveis econômicas, sociais, ambientais e de infraestrutura urbana que podem afetar o crescimento de determinada região e seus vizinhos, a partir de efeitos de transbordamentos espaciais. Dessa forma, ao propor um estudo de crescimento econômico para os estados brasileiros, este artigo destaca a necessidade de se considerar os aspectos espaciais nos modelos tradicionais sobre o tema. Logo, a principal contribuição deste trabalho é analisar o processo de crescimento dos estados brasileiros por meio de um modelo de dados em painel em que eventuais efeitos espaciais sejam considerados.

A proposta de avaliar os efeitos do crescimento econômico no Brasil é aplicada, principalmente, com o recorte territorial para estados ou municípios. Magalhães et al. (2005) investigaram a convergência de renda per capita dos estados brasileiros entre os anos 1970 e 1995. Os autores concluíram que existe dependência espacial entre as Unidades da Federação e, desta forma, sugeriram que os modelos que estudam os estados brasileiros devem considerar a dependência espacial, sob pena de má especificação. Silveira Neto \& Azzoni (2006) também evidenciaram padrões de correlação espacial em estudos de crescimento regional no Brasil.

Resende (2005) especificou um modelo para captar os spillovers que influenciaram as taxas de crescimento de renda per capita nos municípios mineiros no período entre 1991 e 2000. De modo geral, os resultados indicaram que as 
externalidades espaciais afetaram o crescimento da renda por habitante nos municípios, bem como apresentaram transbordamentos para municípios vizinhos. Ferrario et al. (2009), por outro lado, pesquisaram o crescimento econômico espacial dos municípios paranaenses, entre os anos 2000 e 2004.

Os resultados indicaram a presença de clusters do tipo alto-alto e do tipo baixo-baixo, evidenciando autocorrelação positiva do crescimento econômico dos respectivos municípios. Da mesma forma, diversos autores também utilizaram a econometria espacial para mensurar efeitos do crescimento sobre alguma região brasileira (Silveira Neto 2001, Monasterio \& Ávila 2004, Resende $\&$ Silva 2007). Entretanto, esses estudos foram realizados para regiões/estados específicos a partir de dados de corte transversal.

Além disso, o maior aprofundamento e compreensão da relação entre o crescimento econômico e outras variáveis de controle, tais como capital humano, gastos do governo e estoque de capital também constituem preocupações deste estudo. Para tal finalidade, o trabalho propõe o uso de modelos de dados em painel com tratamento da dependência espacial. Outro aspecto que reforça o interesse deste estudo é o uso de uma base de dados que cobre períodos mais recentes: 1992 até 2006. Dessa forma, essa análise permite uma investigação espacial e temporal da evolução econômica no país.

Este artigo está dividido em mais quatro seções, além desta introdução. A segunda seção descreve a modelagem econométrica utilizada no artigo, e em seguida será apresentada a base de dados e o tratamento das variáveis utilizadas no modelo. A quarta seção discutirá os resultados. E, por fim, na última seção são tecidas as considerações finais do trabalho.

\section{Metodologia}

\subsection{Análise Exploratória de Dados Espaciais (AEDE)}

Segundo Anselin (1988), a econometria espacial é considerada um instrumento capaz de quantificar o comportamento atomístico de um determinado agente, de acordo com sua interação em relação a outros agentes heterogêneos presentes no espaço, também heterogêneos. No método, os efeitos espaciais, como a dependência e a heterogeneidade espaciais, são considerados, ao contrário dos métodos econométricos tradicionais. Ressalta-se que é recomendável uma análise exploratória de dados antes de qualquer análise estatística mais sofisticada (Fotheringham et al. 2000). Dessa forma, a utilização de modelos econométricos espaciais permite evitar vários problemas de inferência estatística que gerariam resultados e conclusões incorretos.

Outros problemas devem ser levados em consideração, principalmente devido à autocorrelação espacial e à heterogeneidade espacial. Os autores argumentam que numa cross-section, os dois problemas podem ser equivalentes do ponto de vista da observação, gerando dificuldades em determinar se o problema é ocasionado pela heterocedasticidade ou pela autocorrelação espacial. Com o conjunto de técnicas da AEDE é possível descrever e observar distribuições espaciais, identificando localidades atípicas (outliers espaciais) e investigar padrões de associação espacial (clusters espaciais) (Almeida 2012).

Para a realização da AEDE, das estimações do modelo e das estatísticas de autocorrelação espacial, é importante estabelecer a matriz de pesos espaciais (W). A escolha da matriz deve caracterizar um determinado arranjo espacial das interações resultantes do fato a ser estudado. Assim, a ela deve ser elabo- 
rada com o objetivo de capturar toda a autocorrelação espacial subjacente ao fenômeno em estudo.

É importante que a matriz de pesos espaciais atenda às exigências de regularidade determinada pelas propriedades assintóticas dos testes e estimadores. Anselin (1988) salienta que, na prática, a matriz W adequada deve ser escolhida, algumas vezes, por tentativa e erro. Contudo, grande parte delas nada mais é do que a disposição geográfica das observações, ou também, da contiguidade.

O critério adotado em relação a escolha da matriz de ponderação espacial (W) para a AEDE foi baseado no procedimento de Baumont et al. (2002). A partir da substituição de várias matrizes como, por exemplo, Rainha, Torre, inverso da distância, $\mathrm{k}$ vizinhos mais próximos para $\mathrm{k}=1$ até $\mathrm{k}=20$, a escolha foi feita mediante o maior e mais significativo valor da estatística I de Moran (Montenegro \& Betarelli Junior 2008). Dada a importância da AEDE, seu objetivo neste trabalho é de explorar as características espaciais da variável dependente (taxa de crescimento do PIB per capita). Para tanto, a matriz de peso utilizada refere-se à matriz de proximidade geográfica, cuja convenção de contiguidade é conhecida como torre (rook), na qual gerou o mais alto valor do I de Moran e foi significativo estatisticamente, como pode ser observado no Apêndice 3, para os três períodos sob análise, isto é, período 1 (1992-1996), período 2 (1997-2001) e período 3 (2002-2006).

Para o cálculo da autocorrelação espacial foi utilizada a estatística I de Moran que permitirá verificar a existência ou não de autocorrelação espacial da variável sob análise. A estatística I de Moran é especificada como:

$$
I=\frac{n}{S_{0}} \frac{\sum_{i} \sum_{j} w_{i j} z_{i} z_{j}}{\sum_{i}^{n} z_{i}^{2}}
$$

Ou matricialmente:

$$
I=\frac{n}{S_{o}} \frac{z^{\prime} W z}{z^{\prime} z}
$$

em que $n$ é o número de regiões, $z$ denota os valores da variável de interesse padronizada, $W z$ caracteriza os valores médios da variável de interesse padronizada nos vizinhos, definidos segundo uma matriz de ponderação espacial $W$. Um elemento dessa matriz, referente à região $i$ e à região $j$, é registrado como $w_{i j}$. S0 é igual à operação $\sum \sum w_{i j}$, significando que todos os elementos da matriz de pesos espaciais W devem ser somados (Almeida 2012).

\subsection{Modelo de regressão com dados em painel}

Os dados em painel, também conhecidos como dados combinados, por compreenderem uma combinação de observações em corte transversal e de séries temporais, possuem um conjunto de vantagens. Os benefícios na utilização de dados assim coletados são: i) permite controlar pela heterogeneidade individual e resolver o problema das variáveis omitidas; ii) possuem maiores informações, variabilidade, menor colinearidade entre as variáveis, mais graus de liberdade e maior eficiência; iii) são melhores para estudar a dinâmica de ajustamento; e iv) são mais capazes de identificar e medir efeitos que não seriam detectados em cross-section ou séries de tempo (Baltagi 2005, Elhorst 2003, Hsiao 2003). 
Outra importante vantagem dos dados em painel é a possibilidade de detectar e medir efeitos de uma melhor forma do que quando a observação é realizada por intermédio de corte transversal puro, ou simplesmente, por uma série temporal pura. A inserção de uma dimensão seccional permite ampla variabilidade dos dados, de modo que o uso destes em nível agregado fornece séries mais suaves em relação às séries individuais que servem de base.

Ainda que os modelos tradicionais de painel de dados possam simplesmente acomodar o efeito espacial caracterizado pela heterogeneidade espacial, também chamados de modelos de efeitos não observados, é possível a modelagem desses efeitos por duas maneiras: pelos modelos de dados em painel com efeitos fixos e pelos modelos de dados em painel com efeitos aleatórios. Para a escolha dos dois modelos supracitados, utiliza-se o teste de Hausman ${ }^{1}$ que indica a seleção do modelo entre as opções de efeitos fixos ou aleatórios.

No caso da não existência de efeitos não observados, que devem ser averiguados pelo teste de Breusch Pagan (BP), deve-se estimar o modelo de dados agrupados (pool data) por Mínimos Quadrados Ordinários (MQO) e testar a autocorrelação espacial nos resíduos. O teste BP, baseado no multiplicador de Lagrange, é realizado para verificação dos efeitos não observados, sendo que a hipótese nula implica que a variância dos resíduos devido aos efeitos individuais seja zero, isto é, $\sigma^{2}=0$, e a alternativa, $\sigma^{2} \neq 0$. Não rejeitar a hipótese nula revela a inexistência de efeitos não observados. Na ausência de efeitos não observados e na hipótese da existência de autocorrelação espacial, o trabalho propõe dois modelos para o controle da dependência espacial (SAR ${ }^{2} \mathrm{e}$ $\left.\mathrm{SEM}^{3}\right)$, que serão descritos no próximo item.

\section{Modelo SAR}

Um dos modelos mais usados para a modelagem de correção espacial é o modelo autoregressivo espacial, conhecido como SAR. O intuito desses modelos é usar a mesma ideia dos modelos autoregressivos em séries temporais, por intermédio da incorporação de um termo defasado (lag) entre as variáveis explicativas. Em sua forma simples, o modelo SAR com a inclusão da variável dependente espacialmente defasada é especificado por meio da equação 3 :

$$
y_{t}=\rho W y_{t}+X_{t} \beta+\varepsilon_{t}
$$

Em que $\rho$ é o parâmetro de defasagem auto-regressiva $(-1<\rho<1)$ e $W y_{t}=$ $\left(W y_{1 t}, \ldots, W y_{N T}\right)$ é o vetor da variável dependente defasada; $X_{t}=\left(X_{k t}^{\prime}, \ldots\right.$, $\left.X_{N T}^{\prime}\right)$ é uma matriz de observações das variáveis explicativas e $\beta=\left(\beta_{1}, \ldots, \beta_{k}\right)$ é um vetor de parâmetros a ser estimado.

Cabe ressaltar que, devido a natureza integrada da autocorrelação espacial, a inclusão da variável dependente espacialmente $(\mathrm{Wy})$ seria semelhante à incorporação de uma variável endógena em um sistema de equações simultâneas (Anselin 1992). Neste caso, para contornar este problema far-se-á uso do método das Variáveis Instrumentais (VI).

Vale dizer que para a relevância dos instrumentos é necessário que eles estejam correlacionados com a defasagem espacial da variável dependente, e para a propriedade da exogeneidade é exigido que o conjunto de instrumentos

\footnotetext{
${ }^{1}$ Para maiores detalhes sobre o teste ver Hausman (1978).

${ }^{2}$ Spatial Auto Regressive (SAR).

${ }^{3}$ Spatial Error model, ou conhecido também como Modelo de Erro Espacial (SEM).
} 
não esteja correlacionado com o termo de erro (Almeida 2012). De acordo com Kelejian \& Prucha (1999), os instrumentos para o uso do método são considerados apropriados quando são extraídos do conjunto das defasagens espaciais relacionados às variáveis explicativas exógenas ( $W X$ ou $\left.W_{2} X\right)$.

Algumas vantagens podem ser destacadas pelo método VI, entre elas a de que o método prescinde da condição de normalidade do erro aleatório, sendo assim, uma alternativa à estimação por Máxima Verossimilhança (MV). Da mesma forma, é computacionalmente mais simplificado comparando-se às estimações por MV e Quase Máxima Verossimilhança. Por último, o método VI garante uma estimação consistente dos modelos espaciais, principalmente naqueles em que existem variáveis endógenas entre as variáveis explicativas, sem contar a defasagem espacial (Wy)(Almeida 2012). Em suma, o principal objetivo do método das Variáveis Instrumentais seria corrigir a endogeneidade representada pelo termo $\mathrm{Wy}$.

\section{Modelo SEM}

O modelo SEM parte da especificação de modelos de média móveis para observações no tempo, e a dependêcia espacial pode ser considerada residual, representada pela estrutura autoregressiva de primeira ordem no termo de erro (Almeida 2012).

O modelo SEM com a inclusão de um termo autoregressivo, pode ser expresso da seguinte forma:

$$
\begin{gathered}
y_{t}=X_{t} \beta+\xi_{t} \\
\xi_{t}=\lambda W_{2} \xi_{t}+\varepsilon_{t}
\end{gathered}
$$

Em que $\varepsilon$ denota distribuição normal multivariada, com média zero e matriz de covariância $\sigma^{2} I$; o coeficiente $\lambda$ que representa o parâmetro do erro autoregressivo espacial, revela a intensidade da autocorrelação espacial entre os resíduos da equação observada e acompanha a defasagem $W_{2} \xi_{t}$.

No modelo SEM, os erros relacionados com qualquer observação representam uma média dos erros nas regiões vizinhas, incluindo um componente do erro aleatório (Almeida 2012), de acordo com a equação 4. É oportuno ressaltar que, ao contrário do modelo SAR, os modelos SEM não revelam a variável resposta como uma função direta dos seus lags espaciais. A presença da autocorrelação espacial nos modelos SEM pode ser verificada nos termos de erro Carvalho \& Albuquerque (2010).

De acordo com o Método Generalizado dos Momentos (MGM) de Kelejian Prucha, adaptado para o contexto espacial, a ideia agora é considerar que a equação 4 continue com média zero e variância constante, no entanto, para o termo de erro aleatório não é necessário seguir uma distribuição normal. De maneira simplificada, o estimador MGM de Kelejian Prucha para o modelo SEM especificado pela equação 4, reduz-se ao estimador de Mínimos Quadrados Generalizados Exequíveis (MQGE). Segundo Almeida (2012), a consecução para obter as estimativas do MQGE consistentes e eficientes, é composto pelas seguintes etapas:

a) Obtêm-se os resíduos da estimação da equação 4 por MQO:

$$
\widehat{\xi}=y-X \widehat{\beta}
$$


b) Estima-se a variância segundo a fórmula:

$$
\sigma^{2}=\frac{(\widehat{\xi}-\lambda W \widehat{\xi})(\widehat{\xi}-\lambda W \widehat{\xi})}{n-k}
$$

c) Deste modo, a variância assintótica de $\widehat{\beta}$ é definida como:

$$
\operatorname{Var}(\widehat{\beta})=\sigma^{2}\left[(X-\lambda W X)^{\prime}(X-\lambda W X)\right]^{-1}
$$

d) Transformam-se as variáveis do modelo (4) ao estilo do procedimento de Cochrane-Orcutt, filtrando-as espacialmente do seguinte modo:

$$
\begin{aligned}
& y^{*}=Y-\widehat{\lambda} W y \\
& X^{*}=X-\widehat{\lambda} W X
\end{aligned}
$$

e) O estimador MQGE de $\beta$ do modelo (4) é adquirido regredindo por MQO as variáveis transformadas $y^{*}$ contra $X^{*}$, já obtida a autocorrelação na forma de erro espacial autoregressivo:

$$
\widehat{\beta}_{M Q G E}=\left[X^{* \prime} X^{*}\right]^{-1} X^{*} Y^{*}
$$

Contudo, como não se sabe qual tipo de dependência espacial que o modelo estimado irá apresentar, serão adotados os seguintes procedimentos de estimação, adaptado de Almeida (2012), detalhados a seguir:

a) Fazer o teste de Breusch-Pagan (BP) para verificar se os efeitos não observados são relevantes para serem incorporados ao modelo construído com base na teoria subjacente;

b) Se o teste de BP indicar que a variância dos efeitos não observáveis é estatisticamente igual a zero, deve-se passar para a etapa e. Caso contrário seguir para a próxima etapa;

c) Fazer o teste de Hausman para descobrir qual é o modelo mais apropriado de efeitos não observados: modelos de efeitos fixos ou modelo de efeitos aleatórios;

d) Estimar o modelo de efeitos não observados sem dependência espacial, indicado pelo teste de Hausman;

e) Checar os resíduos para averiguar a presença de dependência espacial;

f) Caso não haja dependência espacial, ficar com os resultados do modelo de efeitos não observados, indicado pelo teste Hausman. Caso contrário, seguir para a etapa i;

g) Se o teste de BP indicar a não existência de efeitos não observados, devese ficar com os resultados do modelo estimado por MQO. Caso contrário, seguir para o próximo passo;

h) Estimar o modelo adotando os métodos recomendados no trabalho (SAR e SEM); 
i) Após a estimação dos modelos supracitados selecionar como o melhor modelo aquele que atender a dois critérios, ordenados em importância:

1) Os resíduos do modelo não apresentam autocorrelação espacial;

2) O modelo apresenta menor critério de informação (critério Akaike), dentre os modelos que não apresentam autocorrelação espacial nos resíduos;

\subsection{Modelo Empírico}

A análise será realizada tendo como referência o modelo econométrico espacial, na forma empilhada, expresso pela equação 12 .

$$
\operatorname{Cresc}_{t}=\alpha+\rho W_{1} \operatorname{Cresc}_{t}+Z_{t} \delta+\varepsilon_{t}
$$

Em que

$$
\varepsilon_{t}=\lambda W_{2} \varepsilon_{t}+\mu_{t}
$$

O termo Cresc $_{t}=\left(\operatorname{Cresc}_{1}, \ldots, \operatorname{Cresc}_{N t}\right)$ é o vetor da taxa de crescimento per capita, representando o crescimento econômico para os estados brasileiros i no período t; $\alpha=\left(\alpha_{1}, \ldots, \alpha_{N}\right)$ representa uma constante; $W_{1}$ é uma matriz de pesos espaciais, de modo que $W_{1} \operatorname{Cresc}_{t}=\left(W_{1} \operatorname{Cresc}_{1 t}, \ldots, W_{1} \operatorname{Cresc}_{N t}\right)$ é o vetor de defasagem espacial da variável dependente e $\rho$ é o coeficiente de defasagem espacial; $Z_{t}=\left(Z_{1 t}, \ldots, Z_{N t}\right)$ é a matriz que representa as demais variáveis explicativas (LPIBt, FECt, EDUCt, INVt, GOVt) e $\delta=\left(\delta_{1}, \ldots, \delta_{k}\right)$ é o vetor de coeficientes; $\varepsilon_{t}=\left(\varepsilon_{1 t}, \ldots, \varepsilon_{N t}\right)$ representa o termo de erro autocorrelacionado; $\mu_{t}=\left(\mu_{1 t}, \ldots, \mu_{N t}\right)$ denota o vetor de erros independentes e identicamente distribuídos (i.i.d) com variância $\sigma^{2} ; \lambda$ significa o coeficiente de autocorrelação espacial do termo de erro; $W_{2}$ revela uma matriz de pesos espaciais, de modo que $W_{2} \varepsilon_{t}=\left(W_{2} \varepsilon_{1 t}, \ldots, W_{2} \varepsilon_{N t}\right)$ representa o vetor de defasagem do termo de erro.

As matrizes $W_{1} e W_{2}$ são diversas captando um efeito mais abrangente ou localizado, e os resultados das especificações quanto ao uso das duas matrizes referem-se para o modelo SAR ou para o modelo SEM, impedindo assim qualquer problema de identificação, principalmente, quanto à especificação do modelo (Anselin \& Bera 1998).

A partir do modelo econométrico expresso na equação 12, econsiderandose os testes de dependência espacial, pretende-se analisar as possíveis modelagens destacadas a seguir. Além disso, como a variável dependente será espacialmente defasada, é bem provável que a autocorrelação espacial esteja vinculada a esta variável. Desse modo, apresenta-se o modelo de defasagem espacial da seguinte forma:

1) Modelo de defasagem espacial (SAR):

$$
\begin{aligned}
\text { Cresc }_{t}= & \alpha+\rho W_{1} \text { Cresc }_{t}+\beta_{1} L P I B+\beta_{2} I N V+ \\
& \beta_{3} F E C+\beta_{4} G O V+\beta_{5} E D U C+\epsilon_{t}
\end{aligned}
$$

Caso o termo de erro considerado $\epsilon_{t}$ siga um processo espacial auto-regressivo, tem-se que:

2) Modelo de erro espacial (SEM): 


$$
\begin{gathered}
\operatorname{Cresc}_{t}=\alpha+\beta_{1} L P I B+\beta_{2} I N V+\beta_{3} F E C+\beta_{4} G O V+\beta_{5} E D U C+\epsilon_{t} \\
\epsilon_{t}=\lambda W_{2} \varepsilon_{t}+\mu_{t}
\end{gathered}
$$

Em que: $\varepsilon_{t}=\left(\varepsilon_{1 t}, \ldots, \varepsilon_{N t}\right)$ é o termo de erro autocorrelacionado; $\mu_{t}=\left(\mu_{1 t}\right.$, ..., $\left.\mu_{N t}\right)$ é um vetor de erros independentes e identicamente distribuídos (i.i.d.) com variância $\sigma^{2} ; \lambda$ representa o coeficiente de autocorrelação espacial do termo de erro; $W_{2}$ representa uma matriz de pesos espaciais, sendo que $W_{2} \varepsilon_{t}=$ $\left(W_{2} \varepsilon_{1 t}, \ldots, W_{2} \varepsilon_{N t}\right)$ é o vetor de defasagem do termo de erro.

\section{Base de dados e descrição das variáveis}

A base de dados utilizada neste trabalho foi elaborada a partir da utilização de diferentes fontes. A taxa de fecundidade e informações sobre o PIB estadual, para a construção das variáveis relacionadas à taxa de crescimento do PIB e a convergência condicional da renda real per capita foram disponibilizadas pelo Ipeadata, tendo como fonte primária o IBGE; dados referentes ao consumo de energia elétrica total foram obtidos a partir do Anuário Estatístico Brasileiro; os anos médios de estudos da população acima de 25 anos, assim como as despesas governamentais foram extraídas da base de dados fornecidas pelo Ipeadata.

O estudo tem como base os anos entre 1992 e 2006 e, conforme alertado na introdução, este é considerado um período de importantes mudanças na economia brasileira. A estimação é realizada por meio da utilização de dados em painel balanceado e a amostra contém 27 estados brasileiros com observações em três subperíodos de tempo não sobrepostos: 1992-1996, 1997-2001, $2002-$ 2006. A literatura de crescimento adota a estratégia de considerar intervalo de tempo a cada dez ou cinco anos, pois o objetivo é evitar que os dados capturem as flutuações de curto prazo. Contudo, antes da descrição das variáveis incluídas no modelo foram realizadas estatísticas descritivas de todas as variáveis, além da matriz de correlação, que possibilita observar se há algum caso de autocorrelação entre as variáveis explicativas. Os resultados encontram-se nos Apêndices 1 e 2, respectivamente.

As variáveis utilizadas no estudo foram as seguintes:

i) A variável dependente (CRESC) é a taxa de crescimento do PIB per capita real entre cada subperíodo destacado anteriormente para o conjunto de todos os 27 estados. Formalmente tem-se que:

$$
\frac{1}{T} \ln \frac{y_{t}}{y_{1-T}}
$$

Em que $y_{t}$ é o PIB per capita real no período final, $y_{1-T}$ é o PIB per capita real do período inicial e $\mathrm{T}$ é o tempo transcorrido do ano inicial para o final. Essa variável foi obtida a partir do IBGE acessado por meio do Ipeadata.

ii) logaritmo do PIB real per capita no início de cada subperíodo (LPIB). Para dados valores das outras variáveis explanatórias, o modelo neoclássico sugere que este coeficiente seja negativo. A ideia é verificar se houve convergência condicional da renda real per capita dos estados. Em outras palavras, se todas as demais variáveis explicativas forem idênticas 
para todos os estados, aqueles com nível de renda per capita mais baixo tenderá a apresentar taxas de crescimento mais elevadas temporariamente.

iii) logaritmo taxa de fecundidade média entre cada subperíodo descrito anteriormente (FEC) - se a população está crescendo, então uma parcela do investimento da economia é usada para fornecer capital para os novos trabalhadores ao invés de expandir o capital por trabalhador e, portanto, um aumento na taxa de crescimento populacional tende a reduzir a taxa de crescimento do PIB real per capita.

iv) o logaritmo da média da formação bruta de capital físico em proporção do PIB entre os subperíodos (INV) - países com altas taxas de investimento devem apresentar maiores taxas de crescimento por favorecer a acumulação de capital. A proxy para investimento é o consumo de energia elétrica total. Existem sérias limitações em relação a essa proxy, ver Figueiredo (2012). Todavia, há uma limitação de dados de energia elétrica para o período proposto neste estudo. A despeito das limitações desta proxy, vários trabalhos empíricos fazem uso de tal variável, Figueiredo et al. (2003), Ferrario et al. (2009), Noronha et al. (2010), Cangussu et al. (2010), entre outros.

v) logaritmo dos gastos médios do governo em proporção do PIB estadual em cada subperíodo (GOV). A medida dos gastos do governo se destina a observar as despesas que não melhoram a produtividade. A conclusão é que maiores volumes de gastos do governo não produtivos reduzam as taxas de crescimento para o dado valor inicial do PIB.

vi) a variável (EDUC) trata-se dos anos médios de estudos da população acima de 25 anos no início de cada subperíodo. O objetivo é capturar o estoque de capital humano e espera-se que estados com maior estoque deste capital apresente taxas de crescimento maiores ao longo do período.

A seguir, na Tabela 1, apresenta-se um resumo relativo às variáveis consideradas para a investigação dos efeitos do crescimento econômico no Brasil sob o período em análise.

\section{Resultados e discussões}

A técnica da Análise Exploratória de Dados Espaciais (AEDE) permitirá identificar e explorar as características espaciais da principal variável sob análise, a taxa de crescimento do PIB, ao longo do período sob estudo (1992 a 2006). O diagnóstico de autocorrelação espacial positiva mostra que há similaridade entre os estados, em outras palavras, há similaridade entre os valores do objeto estudado e da localização espacial do atributo. A autocorrelação espacial positiva revela que, em geral, valores elevados de uma variável de interesse (y) tendem a estar ladeado por altos valores desta variável em regiões vizinhas (Wy) e/ou baixos valor de y tendem a estar ladeado por baixos valores também para y em regiões vizinhas $(\mathrm{Wy})$.

Já no caso de uma autocorrelação espacial negativa haverá uma dissimilaridade entre os valores do objeto em estudo e da localização espacial deste 
Tabela 1: Resumo das variáveis na análise dos efeitos do crescimento econômico sobre os estados brasileiros (1992-2006)

\begin{tabular}{|c|c|c|c|c|c|c|}
\hline Variável & Descrição & Sinal Esperado & Referenciais Teórico e Empírico & Período (anos) & Unidade $^{* *}$ & Fonte \\
\hline CRESC $^{*}$ & Taxa de crescimento do PIB & & & $\begin{array}{l}1992-1996 \\
1997-2001 \\
2002-2006\end{array}$ & $R \$$ & IBGE \\
\hline LPIB & $\begin{array}{l}\text { Convergência condicional } \\
\text { da renda real per capita }\end{array}$ & - & $\begin{array}{l}\text { Solow (1956), Barro (1991), Magalhães } \\
\text { et al. (2005), Silveira Neto \& Azzoni } \\
\text { (2006). }\end{array}$ & $\begin{array}{l}1992 \\
1997 \\
2002\end{array}$ & $R \$$ & IBGE \\
\hline FEC & Proxy para a fecundidade & - & Solow (1956), Figueiredo et al. (2003). & $\begin{array}{l}\text { Média dos períodos: } \\
1992-1996 \\
1997-2001 \\
2002-2006\end{array}$ & $\%$ & IBGE \\
\hline EDUC & Proxy para capital humano & + & $\begin{array}{l}\text { Lucas (1988), Mankiw et al. (1992), } \\
\text { Figueiredo et al. (2003), Barros (2011). }\end{array}$ & $\begin{array}{l}\text { Média dos períodos: } \\
1992-1996 \\
1997-2001 \\
2002-2006\end{array}$ & $\%$ & IBGE \\
\hline INV & $\begin{array}{l}\text { Proxy para estoque de } \\
\text { capital físico }\end{array}$ & + & $\begin{array}{l}\text { Solow (1956), Figueiredo et al. (2003), } \\
\text { Ferrario et al. (2009), Noronha et al. } \\
\text { (2010). }\end{array}$ & $\begin{array}{l}1992-1996 \\
1997-2001 \\
2002-2006\end{array}$ & GWh & $\begin{array}{l}\text { Anuário } \\
\text { Estatístico } \\
\text { Brasileiro }\end{array}$ \\
\hline GOV & Despesas governamentais & - & $\begin{array}{l}\text { Barro (1991), Barro (1996), Lledo \& } \\
\text { Ferreira (1997). }\end{array}$ & $\begin{array}{l}\text { Média dos períodos: } \\
1992-1996 \\
1997-2001 \\
2002-2006\end{array}$ & $R \$$ & Ipeadata \\
\hline
\end{tabular}


atributo. Deste modo, a autocorrelação espacial negativa revela que, por exemplo, um alto valor da variável de interesse de um estado tende a estar rodeado por baixos valores desta mesma variável nos estados vizinhos e/ou um baixo valor da variável de interesse do estado tende a estar ladeado por altos valores desta variável de interesse em estados vizinhos (Almeida 2012).

No diagrama de dispersão de Moran (Figura 1), é possível visualizar o indicador global de autocorrelação espacial para a defasagem espacial da variável dependente, isto é, a média da taxa de crescimento nos vizinhos. A Figura 1 mostra os valores das estatísticas de I de Moran para a variável dependente e, a significância da estatística para seu respectivo período, pode ser visualizada no Apêndice A.1.

Com o diagrama de dispersão é possível visualizar como o indicador global de autocorrelação (I de Moran) se posiciona, isto é, se existe uma autocorrelação positiva da reta de regressão corroborando a autocorrelação espacial positiva dos dados, ou caso contrário, a autocorrelação espacial negativa dos dados (inclinação negativa). A defasagem espacial da taxa de crescimento é localizada no eixo vertical e o valor da taxa de crescimento no eixo horizontal. Os diagramas de dispersão (Figura 1) nos períodos 1 e 2 mostram um coeficiente de autocorrelação espacial positiva em relação a taxa de crescimento estadual. Este resultado indica que uma similaridade entre as Unidades da Federação, isto é, Estados com elevada taxa de crescimento são vizinhos de Estados que exibem comportamento similar.

Na Figura 1 também é possível observar que, além do I de Moran, os diagramas estão divididos em quatro quadrantes, são eles: Alto-Alto (AA), BaixoBaixo (BB), Alto-Baixo (AB) e Baixo-Alto (BA). Apenas o I de Moran do período 1 foi significativo e, portanto, apresentou autocorrelação espacial da taxa de crescimento, conforme os resultados apresentados no Apêndice A.1. Deste modo, apenas seus resultados serão considerados na análise. No primeiro gráfico, referente ao período 1, dentre os Estados localizados no quadrante Alto-Alto, e que também são chamados de pontos de alavancagem ${ }^{4}$, estão, por exemplo: Ceará, Mato Grosso do Sul, Rondônia e Pernambuco. Em relação aos Estados situados no quadrante BA (Acre, Rio de Janeiro, São Paulo e Bahia) e AB (Amazonas e Espírito Santo), eles representam o grupo no qual são vizinhos de Estados com alta e/ou baixas taxas de crescimento.

É interessante notar que apenas no primeiro período analisado, 1992-1996, observa-se correlação espacial positiva e significativa da taxa de crescimento econômico. Nos demais períodos houve uma alteração nessa lógica, a qual será explicitada na seção seguinte. Por intermédio da Figura 2 é possível perceber que, no período 1, somente três Estados apresentaram taxa de crescimento da renda entre $1,4 \%$ a 2,1\%, como foi o caso de Piaúi, Paraíba e Rondônia.

A Figura 2 reflete, em termos gerais, o primeiro indício de convergência de renda entre os estados brasileiros no período analisado. Em outras palavras, as UFs com maior nível de renda, localizadas nas regiões Sul e Sudeste, apresentaram ao longo do tempo taxa de crescimento inferior em relação a alguns estados mais pobres das regiões Norte e Nordeste.

Em relação ao modelo econométrico (Tabela 1), foi estimado para um conjunto de dados em painel composto pelos 27 estados brasileiros, com obser-

\footnotetext{
${ }^{4}$ Considera-se pontos de alavancagem uma observação que, embora seguindo associação espacial idêntica ao restante dos dados, estabelece uma influência exacerbada em relação à determinação do grau de associação espacial (Almeida 2012).
} 

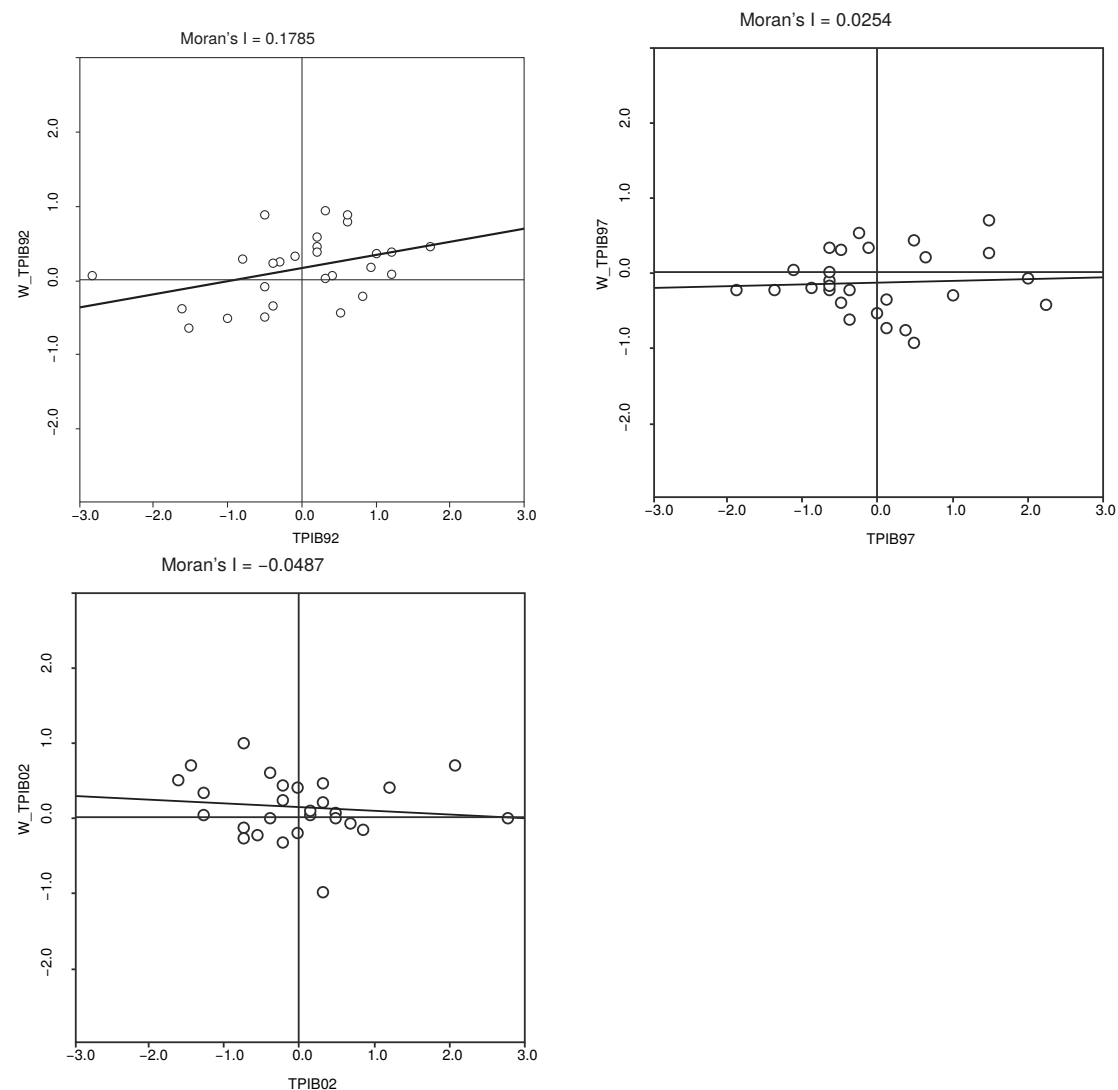

Fonte: Elaboração própria com base no GeodaSpace.

Os padrões de associação espacial são encontrados nos quatro quadrantes do diagrama de dispersão da seguinte forma: Baixo-Alto (BA) localizado no primeiro quadrante; Alto-Alto (AA) no segundo quadrante; Baixo-Baixo (BB) e Alto-Baixo (AB) localizados no terceiro e quarto quadrantes, respectivamente.

Figura 1: Diagrama de dispersão de Moran para a taxa de crescimento do PIB (1992-2006)

vações para o período de 1992 a 2006. O objetivo deste item é analisar a significância das variáveis e os testes de especificação realizados. A partir dos procedimentos de estimação descritos na seção metodológica, é possível observar na Tabela 2 que o teste de Breusch Pagan, realizado após as estimações do modelo com efeitos aleatórios indica a ausência de efeitos não observados, sob a hipótese nula de que $\sigma^{2}=0$.

Os resultados estimados por MQO estão condizentes com o esperado para a maioria das variáveis. Note que o logaritmo do PIB no início de cada período foi negativo e significativo em todas as especificações. Isto aponta para a ideia de convergência condicional que, segundo Barro \& Sala-I-Martin (2003) é o resultado mais robusto nos modelos de crescimento. O mesmo se observa para a taxa de fecundidade. O resultado negativo e significativo para os gastos do governo sugerem que na medida em que se elevam as despesas que não melhoram a produtividade, a tendência é que haja uma redução das taxas de crescimento. As três especificações apontam que o estoque de capital humano afeta positivamente as taxas de crescimento do período subsequente. A única variável que não apresentou o resultado esperado foi a proxy que deveria me- 

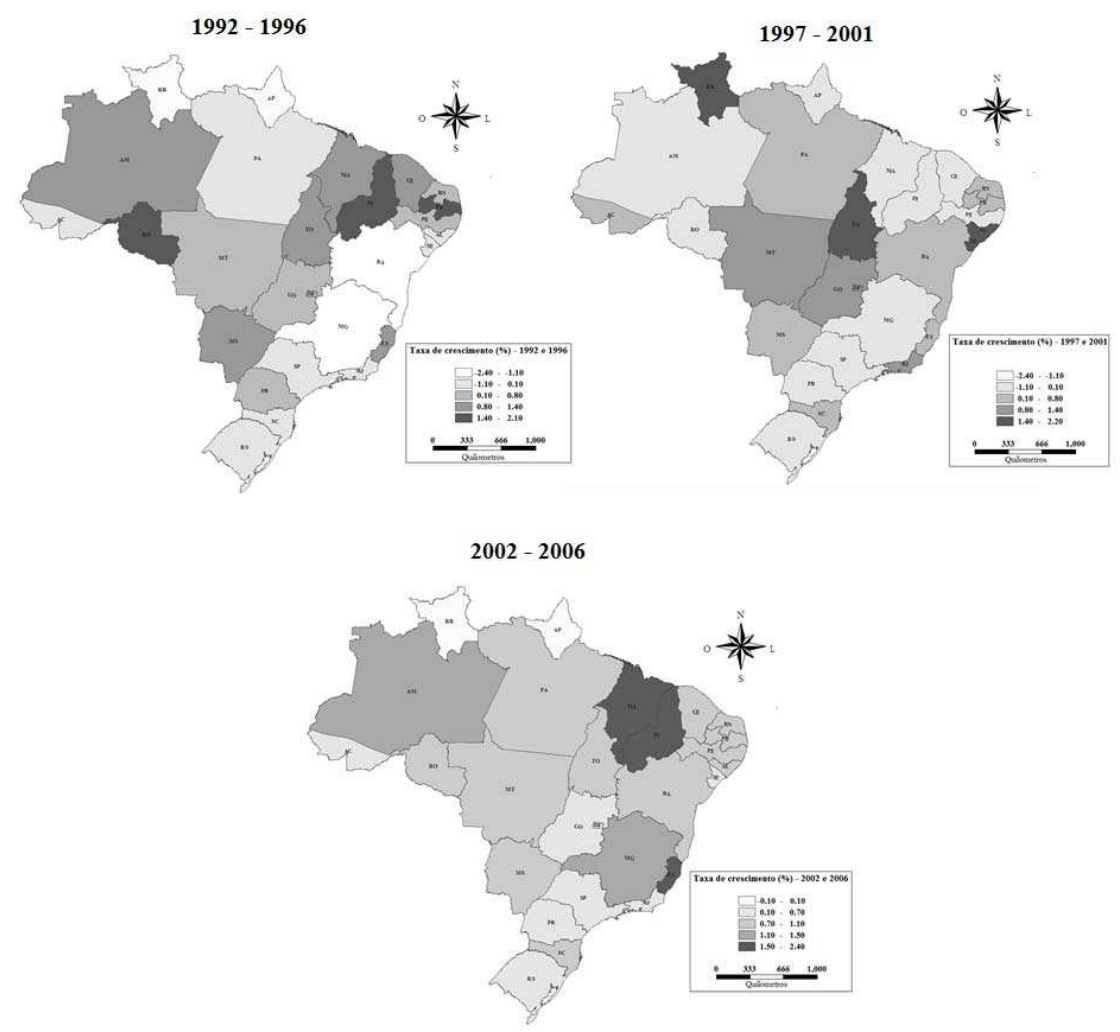

Fonte: Elaboração própria dos autores com base no programa ArcView.

Figura 2: Análise da taxa de crescimento nos estados brasileiros (1992-2006)

dir o estoque de capital físico. No entanto, duas questões podem justificar esse fato. A primeira é decorrente da fragilidade dessa proxy conforme alertado na seção anterior. Em segundo lugar, os modelos expostos anteriormente não consideram eventuais problemas de endogeneidade, mas tais questões serão abordadas a seguir. O teste Breusch \& Pagan (1980) é um teste simples e muito usado para testar a presença de efeitos não observáveis.

No entanto, Bera et al. (2001) demonstraram que, na presença de correlação serial de primeira ordem, este teste muitas vezes rejeita a correta hipótese nula de efeitos não aleatórios. Então, esses autores propõem uma versão modificada que não é afetada pela presença de correlação serial local. Algumas outras importantes modificações deste teste foram elaboradas por Baltagi \& Li (1990, 1991). O valor calculado do teste de Bera et al. (2001) foi 1.05 sob a hipótese nula que $\operatorname{Var}(\mathrm{u})=0$ e um $\mathrm{p}$-value igual a 0.30 . Logo, não se rejeita a hipótese nula de que a variância do componente não observado é zero. Além disso, nota-se ausência da autocorrelção serial, cuja presença comprometeria os resultados do teste convencional de Breusch \& Pagan (1980), posto que o valor da estatística, lambda $=0$, foi 2.10 com um $p$-value igual a 0.14 . Por fim, o teste conjunto de Baltagi \& Li (1991) de que $\operatorname{Var}(\mathrm{u})=0$ e lambda=0 apresentou um valor calculado igual a $3.15 \mathrm{com}$ um p-value de 0.20 . Todos esses testes apontam para a ausência de efeitos não observados e, portanto, os modelos podem ser estimados como um pooled MQO. Ainda assim, optou-se por apresentar o teste de Hausman. 
Tabela 2: Resultados dos modelos estimados por MQO, Efeitos Fixo (EF) e Aleatório (EA)

\begin{tabular}{lcll}
\hline Variáveis & Modelo MQO & Modelo EF & Modelo EA \\
\hline Constante & $0,1516^{* * *}$ & $0,2225^{* *}$ & $0,1517^{* * *}$ \\
& $(6,29)$ & $(2,36)$ & $(6,29)$ \\
LPIB & $-0,0180^{* * *}$ & $-0,0313^{* * *}$ & $-0,0180^{* * *}$ \\
& $(-5,00)$ & $(-6,12)$ & $(-5,00)$ \\
FEC & $-0,0235^{* * *}$ & $-0,0298^{* *}$ & $-0,0235^{* * *}$ \\
EDUC & $(-4,40)$ & $(-2,21)$ & $(-4,40)$ \\
& $0,0398^{* * *}$ & $0,0053^{* *}$ & $0,0040^{* * *}$ \\
INV & $(2,88)$ & $(2,88)$ & $(2,88)$ \\
& $-0,0028^{* * *}$ & $0,0004^{*}$ & $-0,0029^{* * *}$ \\
GOV & $(-2,72)$ & $(0,03)$ & $(-2,72)$ \\
& $-0,0151^{* * *}$ & $-0,0217^{* * *}$ & $-0,0151^{* * *}$ \\
\hline$R^{2}$ & $(-3,45)$ & $(-3,32)$ & $(-3,45)$ \\
Node observações & 0,3494 & 0,3738 & 0,3654 \\
Teste de Breusch Pagan & chi2 $2(1)=1,05$ & 81 & Prob $>$ chi2 $=0,3055$ \\
Teste de Hausman & chi2 $(5)=6,49$ & Prob $>$ chi2 $=0,2612$ \\
\hline
\end{tabular}

Fonte: Elaboração própria dos autores com base no programa Stata 10.0. Variável

dependente: Cresct;

Nota: ${ }^{* * *}$ significativo a $1 \%$;

** significativo à 5\%;

* Não significativo;

Observação: O desvio padrão se encontra entre parênteses.

Nota: A estatística t se encontra entre parêntesis, com exceção do modelo de EA, na qual é apresentada a estatística $z$.

O próximo passo do procedimento de estimação refere-se a verificação dos resíduos para averiguar se há a presença da dependência espacial. Conforme os resultados do teste de I de Moran (Tabela A.2), observou-se que a matriz $\mathrm{k}=3$ obteve o maior valor da estatística de autocorrelação e foi significativa a $10 \%$. A escolha da matriz de ponderação espacial teve como base o procedimento de Baumont $(2004)^{5}$. Evidenciado a dependência espacial nos resíduos, estimou-se os modelos recomendados na metodologia, a saber, os modelos SAR e SEM (Tabela 3).

A defasagem espacial dos resíduos do modelo SEM foi elaborada utilizando uma matriz de ponderação espacial diferente evitando assim, qualquer problema de identificação quanto à especificação do modelo. A seleção da matriz baseou-se naquela que obteve o segundo mais alto valor do teste I de Moran (distância inversa), cujo resultado pode ser observado na Tabela A.2. Quanto aos resultados das estimações cujas variáveis foram filtradas espacialmente e a estimação foi realizada por MQO, observa-se que, com exceção da variável de erro e da constante, todas as demais variáveis não foram significativas, e além disso, a maioria das variáveis não apresentou o sinal teórico esperado.

Para o procedimento de estimação do modelo SAR, e partindo do pressuposto de que a inclusão no modelo da variável defasada espacialmente implica

\footnotetext{
${ }^{5} \mathrm{O}$ procedimento de Baumont (2004) utiliza os resíduos da regressão do modelo clássico de regressão linear (MQO) e, pelo teste de autocorrelação espacial (I de Moran), utilizando-se matrizes espaciais de contiguidade geográfica e de $\mathrm{k}$ vizinhos mais próximos, variando de $\mathrm{k}=1 \mathrm{a} \mathrm{k}=20$, a seleção da matriz é baseada naquela em que tenha gerado o maior valor de I de Moran e, que seja significativa estatisticamente.
} 
Tabela 3: Resultados e testes econométricos dos modelos espaciais (SAR e SEM) para o crescimento econômico

\begin{tabular}{|c|c|c|}
\hline Variáveis & Modelo SAR & Modelo SEM \\
\hline Constante & $\begin{array}{c}0,1334^{* * *} \\
(4,19)\end{array}$ & $\begin{array}{c}0,0095^{* * *} \\
(2,85)\end{array}$ \\
\hline LPIB & $\begin{array}{c}-0,0170^{* * *} \\
(-4,56)\end{array}$ & $\begin{array}{c}0,0007^{*} \\
(0,37)\end{array}$ \\
\hline FEC & $\begin{array}{l}-0,0207^{* * *} \\
(-2,56)\end{array}$ & $\begin{array}{c}-0,0052^{*} \\
(-1,21)\end{array}$ \\
\hline EDUC & $\begin{array}{c}0,0039^{* * *} \\
(2,63)\end{array}$ & $\begin{array}{c}-0,0007^{*} \\
(-0,54)\end{array}$ \\
\hline INV & $\begin{array}{c}-0,0016^{*} \\
(-0,77)\end{array}$ & $\begin{array}{c}-0,0005^{*} \\
(0,38)\end{array}$ \\
\hline GOV & $\begin{array}{c}-0,0122^{* *} \\
(-2,23)\end{array}$ & $\begin{array}{c}0,0009^{*} \\
(0,19)\end{array}$ \\
\hline W_CRESC & $\begin{array}{c}0,4155 \\
(1,08)\end{array}$ & \\
\hline$\lambda$ & & $\begin{array}{l}0,93482^{* * *} \\
(4,73)\end{array}$ \\
\hline$R^{2}$ & 0,5129 & 0,4005 \\
\hline I de Moran & $\begin{array}{l}\text { Sem dependência } \\
\text { espacial }\end{array}$ & $\begin{array}{l}\text { Dependência } \\
\text { espacial }\end{array}$ \\
\hline Akaike & $-565,0823$ & $-570,4$ \\
\hline Schwarz & $-548,3211$ & $-553,6375$ \\
\hline $\begin{array}{l}\text { Teste de Kleibergen-Paap } \\
\text { (Multiplicador de Lagrange) }\end{array}$ & 16.19 & $\mathrm{p}$-value $=0.0028$ \\
\hline Teste de Hansen & 4,124 & $\mathrm{p}$-value $=0.2484$ \\
\hline
\end{tabular}

em incluir uma variável endógena, utilizou-se as variáveis defasadas espacialmente como instrumentos (método VI). Vale ressaltar que foi computada a defasagem espacial utilizando-se a matriz de peso espacial $(\mathrm{k}=3)$ da variável dependente e das variáveis explicativas.

O modelo foi estimado pelo Método Generalizados do Momentos (GMM). É importante verificar a validade dos instrumentos utilizados nos modelos. Isto pode ser verificado por meio do teste de Shea (1997) e de Kleinbergen \& Paap (2006). Aqui, a hipótese nula de ambos os testes é rejeitada a $1 \%$ de significância, confirmando a importância dos instrumentos para explicar o desempenho das variáveis. Em seguida, foi realizada a estatística J de Hansen, que avalia a sobreidentificação dos instrumentos. A hipótese nula é de que todos os instrumentos não são correlacionados com o erro e, de acordo com os resultados da Tabela 3, não se rejeita a hipótese nula de ortogonalidade entre os instrumentos e a perturbação estocástica, no qual a sobreidentificação é válida. A combinação das duas estatísticas revela que os instrumentos atendem os critérios de sustentabilidade da estimação, corroborada pela não rejeição da hipótese nula do teste de sobreidentificação dos instrumentos.

Outro elemento que ratifica o ajuste do modelo SAR, e é considerado o mais importante, foi o teste dos resíduos (Tabela 4), realizado a partir do teste 
de I de Moran, após a estimação dos modelos econométricos espaciais SAR e SEM. Apesar do critério de informação Akaike (AIC) no modelo SEM ter apresentado o menor valor, o primeiro e mais importante critério é de que os resíduos não apresentem autocorrelação espacial. E, nesse caso, os resultados indicam que não há dependência espacial para o modelo SAR nos três períodos sob análise. Entretanto, no modelo SEM, há presença de autocorrelação espacial no período 2 (1997-2001).

Tabela 4: Indice de Moran dos resíduos para o modelo SAR e SEM

\begin{tabular}{lccccc}
\hline \multicolumn{5}{c}{ Modelo de defasagem (SAR) } \\
\hline Período & I de Moran & Probabilidade & Média & Desvio-padrão & Z-valor \\
\hline 1 & $-0,3039$ & 0,2130 & $-0,0351$ & 0,1326 & $-2,0265$ \\
2 & $-0,0437$ & 0,4800 & $-0,0385$ & 0,1359 & $-0,0378$ \\
3 & $-0,0866$ & 0,3630 & $-0,0300$ & 0,1375 & $-0,4118$ \\
\hline \multicolumn{7}{c}{ Modelo de erro (SEM) } \\
\hline Período & I de Moran & Probabilidade & Média & Desvio-padrão & Z-valor \\
\hline 1 & $-0,0312$ & 0,4810 & $-0,0301$ & 0,1422 & $-0,0082$ \\
2 & 0,2332 & 0,0260 & $-0,0414$ & 0,1318 & 2,0829 \\
3 & 0,1237 & 0,1180 & $-0,0391$ & 0,1354 & 1,2024 \\
\hline
\end{tabular}

Fonte: Elaboração própria dos autores com base do GeodaSpace.

Nota: a matriz espacial utilizada para o teste foi $k=3$.

De acordo com os critérios observados anteriormente, o modelo de defasagem espacial (SAR) apresentou-se como o mais adequado na estimação dos efeitos de crescimento econômico.

Em primeiro lugar, o que se deve notar é que as principais variáveis estão de acordo com o esperado em todas as especificações. Isto é, a proxy de capital humano tem efeitos positivos sobre as taxas de crescimento econômico. Taxa de fecundidade, gastos do governo e logaritmo do PIB apresentaram sinais negativos e significativos, conforme já explicados anteriormente. Quanto a proxy do investimento, as estimativas por MQO sugeriam, contraditoriamente, que um aumento na formação de capital fixo reduziria o crescimento econômico. Umas das hipóteses foi que ou a proxy de energia utilizada não é adequada, tal como sugerem alguns trabalhos, ou talvez seja um problema de endogeneidade. Os modelos acima descritos consideraram tal variável como endógena e utilizou-se sua defasagem espacial como instrumento. Ao adotar este procedimento, a variável perde significância apesar do instrumento ser adequado. Logo, é possível que, de fato, esta proxy não seja adequada.

A variável dependente defasada espacialmente não foi significativa indicando, portanto, que a taxa de crescimento de um determinado estado não é afetada significativamente pelo crescimento do vizinho. Contudo, a inclusão dessa variável foi suficiente para eliminar a dependência espacial que estava presente nos resíduos. As taxas de crescimento entre os estados brasileiros não parecem depender das fronteiras físicas. Basta notar que os estados do Sudeste, e São Paulo em particular, são grandes fornecedores de bens, dos mais diversos, para o resto do país, e, no entanto, eles fazem fronteira apenas com poucos estados.

Este resultado também pode ser justificado, em parte, pela Lei de Tobler (1970, p.236): "everything is related to everything else but nearby things are more related than distant things". Em outras palavras, é de se esperar uma relação 
espacial mais forte entre unidades espaciais menores do que estados como é o caso, por exemplo, de microrregiões ou municípios.

A maior parte dos estudos desenvolvidos para o Brasil apontou alguma relação de transbordamento (spillover) da taxa de crescimento para os seus vizinhos. Silveira Neto (2001), por exemplo, estudou a presença de spillovers de crescimento entre as economias dos estados brasileiros para o período 19851997. Seu estudo é uma cross-section e as estimativas são realizadas por MQO e por Máxima Verossimilhança. Este autor afirma que o crescimento das economias vizinhas afeta o crescimento dos estados. Ou seja, existem spillovers de crescimento regionais entre as UFs. Ele utiliza várias medidas de proximidade e sugere que os transbordamentos são mais importantes entre os estados mais próximos. Notou-se, também, que enquanto o crescimento da renda per capita dos estados não é afetado pela riqueza de seus vizinhos, o tamanho de mercado destes influencia este crescimento.

Em relação a análises aplicadas a municípios, Monasterio \& Ávila (2004) e Ferrario et al. (2009), evidenciaram, respectivamente, a presença de autocorrelação positiva na taxa de crescimento dos municípios gaúchos entre 1939 e 2001 e paranaenses entre 2000 e 2004 . Ou seja, o crescimento da vizinhança de um município afeta positivamente o seu crescimento econômico.

Alguns resultados observados neste artigo diferem substancialmente daqueles antecitados. No processo de estimação do modelo espacial com dados em painel, por exemplo, a dependência espacial dos resíduos foi analisada período a período. Como a dependência espacial foi verificada apenas no primeiro período analisado, entre 1992 e 1996, é possível que ao longo do tempo a associação entre crescimento econômico e espaço talvez esteja se perdendo.

Além de adotar o método de dados em painel, este trabalho utilizou um período de tempo que se inicia nos primeiros anos da década de 90 e se estende até o ano de 2006. Ademais, outra diferença em relação aos estudos anteriores é que, aqui, utilizam-se estimativas pelo GMM considerando, assim, a presença de possíveis variáveis endógenas. Uma das principais conclusões do artigo foi que as taxas de crescimento dos vizinhos não afetam significativamente as taxas de crescimento dos estados. No entanto, a especificação mais correta do modelo exige a consideração do elemento espacial, haja vista a presença de autorrelação espacial nos resíduos entre os anos de 1992 e 1996.

\section{Considerações finais}

O objetivo deste artigo foi analisar o processo de crescimento econômico dos 27 estados brasileiros entre os anos 1992 e 2006 por meio do modelo de dados em painel com tratamento da dependência espacial. Pela análise exploratória dos dados espaciais (AEDE) foi possível visualizar indícios de convergência de renda entre os estados. Ou seja, as Unidades de Federação com maior nível de renda, principalmente, aquelas situadas nas regiões Sul e Sudeste, apresentaram ao longo do tempo um crescimento econômico inferior quando comparado aos estados mais pobres das regiões Norte e Nordeste. Esses indícios foram confirmados quando da estimação econométrica.

Dentre os principais resultados obtidos pela análise econométrica, observouse que a convergência condicional de renda entre os estados brasileiros, a taxa de fecundidade e os gastos do governo possuem um efeito negativo sobre o crescimento econômico. Por outro lado, anos de estudo, proxy para o capi- 
tal humano, apresentou um efeito positivo sobre o crescimento. Em relação ao consumo de energia elétrica total, proxy para capital físico, embora tenha apresentado sinal positivo, não foi significativa estatisticamente. Conforme dito anteriormente, talvez essa proxy não seja a mais adequada. Porém, em virtude da dificuldade de obtenção de outras proxies para o período em questão e para a unidade espacial utilizada, optou-se pela utilização dessa variável até porque outros trabalhos relevantes também o fazem.

Por fim, o principal resultado encontrado no trabalho mostra que a taxa de crescimento dos estados brasileiros não é afetada significativamente pelo crescimento dos seus vizinhos. Essa evidência, apesar de diferir de outros estudos realizados para o Brasil, sugere que os Estados possuem mecanismos mais autônomos de crescimento quando comparados a unidades espaciais menores (microrregiões ou municípios).

A despeito da variável dependente defasada espacialmente não ter apresentado significância estatística em todos os anos, considera-se importante que a especificação do modelo contenha o elemento espacial. Isso acontece porque se verifica a presença de autocorrelação espacial dos resíduos no primeiro ano de análise. É razoável supor que com a integração regional e com o desenvolvimento das tecnologias de informação as relações econômicas entre os estados brasileiros tenham rompido as fronteiras geográficas e, assim, os transbordamentos de crescimento para o estado vizinho perderam relevância. É evidente que essas conclusões precisam ser corroboradas com estudos que levem em conta um período de tempo maior.

\section{Referências Bibliográficas}

Almeida, E. (2012), Econometria espacial aplicada, Editora Alínea, São Paulo.

Anselin, L. (1988), Spatial econometrics: methods and models, Kluwer Academic, Boston.

Anselin, L. (1992), 'Spacestat tutorial', University of Illinois.

URL: Disponivel em: <http://siteresources.worldbank.org/INTPGI/Resources/342674-1092157888460/Anselin.spacestatTutorial.pdf $>$ Acesso em: 30 out. 2013

Anselin, L. \& Bera, A. K. (1998), Spatial dependence in linear regression models with an introduction to spatial econometrics, in A. Ullah \& D. Giles, eds, 'Handbook of Applied Economic Statistics', Vol. capítulo 7, Marcel Deckker.

Baltagi, B. (2005), Econometric analysis of panel data, third edn, John Wiley \& Sons, Chichester.

Baltagi, B. H. \& Li, Q. A. (1990), 'A lagrange multiplier test for the error components model with incomplete panels', Econometric Reviews 9(1), 103107.

Baltagi, B. \& Li, Q. A. (1991), 'A joint test for serial correlation and random individual effects', Statistics and Probability Letters 11(3), 277-280.

Barro, R. J. (1991), 'Economic growth in a cross section of countries', Quarterly Journal of Economics 2(106), 407-443. 
Barro, R. J. (1996), 'Democracy and growth', Journal of Economic Growth 1(1), 1-27.

Barro, R. J. \& Sala-I-Martin, X. (2003), Economic Growth, second edn, MIT Press, Cambridge.

Barros, R. A. (2011), Desigualdades regionais no Brasil: naturezas, causas, origens e solução, Elsevier, Rio de Janeiro.

Baumont, C. (2004), 'Spatial effects in housing price models: do housing prices capitalize urban development policies in the agglomeration of dijon (1999)?', Universite de Bourgogne, França.

URL: Disponivel em: <http://leg2.u-bourgogne.fr/documents-de-travail/e200404.pdf> Acesso em: 31 out. 2013

Baumont, C., Ertur, C. \& Le Gallo, J. (2002), 'The european regional convergence process 1980-1995: do spatial regimes and spatial dependence matter ?', University of Burgundy, França.

URL: Disponivel em: < http://128.118.178.162/eps/em/papers/0207/0207002.pdf>. Acesso em: 31 out. 2013

Becker, G. S. (1964), Human capital a theoretical and empirical analysis with special reference to education, Columbia University Press, New York.

Bera, A., Sosa-Escudero \& Yoon, M. (2001), 'Tests for the error component model in the presence of local misspecification', Journal of Econometrics 101(1), 1-23.

Breusch, T. \& Pagan, A. (1980), 'The lagrange multiplier test and its applications to model specification in econometrics', Review of Economic Studies 47(1), 239-253.

Cangussu, R. C., Salvato, M. A. \& Nakabashi, L. (2010), 'Uma análise do capital humano sobre o nível de renda dos estados brasileiros: Mrw versus mincer', Estudos Econômicos 1(40), 153-183.

Carvalho, A. X. Y. \& Albuquerque, P. H. M. (2010), Tópicos em econometria espacial para dados cross-section, Texto para discussão 1508, IPEA.

Domar, E. O. (1946), 'Capital expansion, rate of growth and employment', Econométrica 14(2), p. 137-147.

Elhorst, J. P. (2003), 'Specification and estimation of spatial panel data models', International Regional Science Review 26(3), 244-268.

Ferrario, M. N., Santos, A. A. \& Parré, J. L., L. R. L. (2009), 'Uma análise espacial do crescimento econômico do estado do paraná para os anos $2000 \mathrm{e}$ 2004', Revista Brasileira de Estudos Regionais e Urbanos 3(1), 154-177.

Figueiredo, L. (2012), Decomposição de nível para os estados brasileiros: 1970-2010, Texto para discussão 466, Cedeplar/UFMG.

Figueiredo, L., Noronha, K. V, K. \& Andrade, M. V. (2003), Os impactos da saúde sobre o crescimento econômico na década de 90: uma análise para os estados brasileiros, Texto para discussão 219, Cedeplar/UFMG. 
Fotheringham, A. S., Brunsdon, C. \& CHARLTON, M. (2000), Quantitative geography: perspectives on spatial data analysis, Sage publications, Londres.

Fujita, M., Krugman, P. R. \& Venables, A. (1999), The spatial economy: cities, regions and international trade, MIT Press, Cambridge.

Harrod, R. F. (1939), 'An essay in dynamic theory', The Economic Journal 49(193), 14-33.

Hausman, J. A. (1978), 'Specification tests in econometrics', Econometrica 46(6), 1251-1271.

Hsiao, C. (2003), Analysis of panel data, second edn, Cambridge University Press, Nova York.

Kelejian, H. H. \& Prucha, I. R. A. (1999), 'Generalized moments estimator for the autoregressive parameter in a spatial model', International Economic Review 40(2), 509-533.

Kleinbergen, F. \& Paap, R. (2006), 'Generalized reduced rank tests using the singular value decomposition', Journal of Econometrics 133(1), 97-126.

Lledo, V. \& Ferreira, P. C. V. (1997), 'Crescimento endógeno, distribuição de renda e política fiscal: uma análise cross section para os estados brasileiros', Pesquisa e Planejamento Econômico 27(1), 41-70.

Lucas, J. R. E. (1988), 'On the mechanics of economic development', Journal of Monetary Economics 22(1), 03-42.

Magalhães, A., Hewings, G. \& Azzoni, C. R. (2005), 'Spatial dependence and regional convergence in brazil', Investigaciones Regionales (6), 05-20.

Mankiw, N., Romer, D. \& Weil, D. A. (1992), 'Contribution to the empirics of economic growth', The Quarterly Journal of Economics 107(2), 407-437.

Monasterio, L. M. \& Ávila, R. P. (2004), 'Uma análise espacial do crescimento econômico do rio grande do sul (1939-2001)', Economia 5(2), 269-296.

Montenegro, R. L. G. \& Betarelli Junior, A. A. (2008), 'Análise e investigação dos fatores determinantes da inovação nos municípios de são paulo', Revista Brasileira de Estudos Regionais e Urbanos 2(2).

Noronha, K., Figueiredo, L. \& Andrade, M. V. (2010), 'Health and economic growth among the states of brazil from 1991 to 2000', Revista Brasileira de Estudos Populacionais 27(2), 269-283.

Resende, G. M. (2005), 'Crescimento econômico dos municípios mineiros: externalidades importam?', Cadernos BDMG (11), 5-33.

Resende, G. M. \& Silva, A. M. A. (2007), 'Crescimento econômico dos municípios da região sul do brasil: uma análise espacial', Ensaios FEE 28(2), 549576.

Romer, M. P. (1990), 'Endogenous technological change', Journal of Political Economy 98(5), 71-102. 
Romer, P. M. (1986), 'Increasing returns and long run growth', Journal of Political Economy 94(5), 1002-1037.

Shea, J. (1997), 'Instrument relevance in multivariate linear models: a simple measure', The Review of Economics and Statistics 79(2), 348-352.

Silveira Neto, R. (2001), 'Crescimento e spillovers: a localização importa? evidências para os estados brasileiros', Revista Econômica do Nordeste 32(Número Especial), 524-545.

Silveira Neto, R. \& Azzoni, C. R. (2006), 'Location and regional income disparity dynamics: the brazilian case', Papers in Regional Science 85(4), 599-613.

Solow, R. M. (1956), 'A contribution to the theory of economic growth', Quarterly Journal of Economics 70(1), 65-94.

\section{Apêndice A}


Tabela A.1: Teste de dependência espacial para a variável dependente (taxa de crescimento)

\begin{tabular}{|c|c|c|c|c|c|c|c|c|c|c|c|c|}
\hline \multicolumn{13}{|c|}{ Matrizes } \\
\hline Período 1 & Rainha & Torre & Distância inversa & $\mathrm{k}=1$ & $\mathrm{k}=2$ & $\mathrm{k}=3$ & $\mathrm{k}=4$ & $\mathrm{k}=5$ & $\mathrm{k}=6$ & $\mathrm{k}=7$ & $\mathrm{k}=8$ & $\mathrm{k}=9$ \\
\hline I de Moran & 0,1785 & 0,1785 & 0,0275 & 0,2103 & 0,1060 & 0,1350 & 0,0809 & $-0,0208$ & $-0,0164$ & $-0,0393$ & $-0,0550$ & $-0,0845$ \\
\hline p-value & 0,0640 & 0,0540 & 0,1980 & 0,1250 & 0,1750 & 0,1100 & 0,1460 & 0,4110 & 0,3640 & 0,4740 & 0,4690 & 0,2670 \\
\hline Média & $-0,0414$ & $-0,0446$ & $-0,0424$ & $-0,0352$ & $-0,0414$ & $-0,0429$ & $-0,0353$ & $-0,0358$ & $-0,0372$ & $-0,0303$ & $-0,0407$ & $-0,0388$ \\
\hline Desvio-padrão & 0,1382 & 0,1335 & 0,0932 & 0,2144 & 0,1580 & 0,1352 & 0,1105 & 0,0958 & 0,0855 & 0,0815 & 0,0683 & 0,0669 \\
\hline z-value & 1,5911 & 1,6712 & 0,7505 & 1,1449 & 0,9331 & 1,3160 & 1,0516 & 0,1571 & 0,2443 & $-0,1108$ & $-0,2091$ & $-0,6831$ \\
\hline Período 2 & Rainha & Torre & Distância inversa & $\mathrm{k}=1$ & $\mathrm{k}=2$ & $\mathrm{k}=3$ & $\mathrm{k}=4$ & $\mathrm{k}=5$ & $\mathrm{k}=6$ & $\mathrm{k}=7$ & $\mathrm{k}=8$ & $\mathrm{k}=9$ \\
\hline I de Moran & 0,0254 & 0,0254 & $-0,1268$ & 0,2645 & 0,0483 & 0,0286 & 0,0122 & $-0,0792$ & $-0,1195$ & $-0,1111$ & $-0,1078$ & $-0,0972$ \\
\hline $\mathrm{p}$-value & 0,3120 & 0,3090 & 0,1690 & 0,0960 & 0,3170 & 0,2690 & 0,3070 & 0,3400 & 0,1780 & 0,1630 & 0,1570 & 0,1560 \\
\hline Média & $-0,0472$ & $-0,0400$ & $-0,0467$ & $-0,0413$ & $-0,0344$ & $-0,0443$ & $-0,0365$ & $-0,0297$ & $-0,0384$ & $-0,0395$ & $-0,0436$ & $-0,0391$ \\
\hline Desvio-padrão & 0,1372 & 0,1398 & 0,0926 & 0,2280 & 0,1622 & 0,1336 & 0,1197 & 0,1020 & 0,0897 & 0,0743 & 0,0678 & 0,0648 \\
\hline $\mathrm{z}$-value & 0,5292 & 0,4677 & $-0,8650$ & 1,3412 & 0,4976 & 0,5459 & 0,4069 & $-0,4856$ & $-0,9030$ & $-0,9630$ & $-0,9464$ & $-0,8965$ \\
\hline Período 3 & Rainha & Torre & Distância inversa & $\mathrm{k}=1$ & $\mathrm{k}=2$ & $\mathrm{k}=3$ & $\mathrm{k}=4$ & $\mathrm{k}=5$ & $\mathrm{k}=6$ & $\mathrm{k}=7$ & $\mathrm{k}=8$ & $\mathrm{k}=9$ \\
\hline I de Moran & $-0,0487$ & $-0,0595$ & $-0,0595$ & $-0,0596$ & $-0,0657$ & $-0,0406$ & $-0,0241$ & $-0,0288$ & 0,0155 & 0,0158 & 0,0181 & 0,0010 \\
\hline p-value & 0,4830 & 0,4420 & 0,4060 & 0,4420 & 0,4450 & 0,4910 & 0,4360 & 0,4190 & 0,2530 & 0,2200 & 0,1690 & 0,2370 \\
\hline Média & $-0,0436$ & $-0,0423$ & $-0,0354$ & $-0,0376$ & $-0,0376$ & $-0,0377$ & $-0,0351$ & $-0,0387$ & $-0,0365$ & $-0,0384$ & $-0,0402$ & $-0,0370$ \\
\hline Desvio-padrão & 0,1392 & 0,0928 & 0,0922 & 0,2134 & 0,1580 & 0,1310 & 0,1130 & 0,0955 & 0,0857 & 0,0757 & 0,0662 & 0,0628 \\
\hline z-value & $-0,0362$ & $-0,1855$ & $-0,2618$ & $-0,1027$ & $-0,1779$ & $-0,0219$ & 0,0971 & 0,1035 & 0,6065 & 0,7153 & 0,8802 & 0,6054 \\
\hline
\end{tabular}

Fonte: Elaboração própria dos autores. 
Tabela A.1: Teste de dependência espacial para a variável dependente (taxa de crescimento) (continuação)

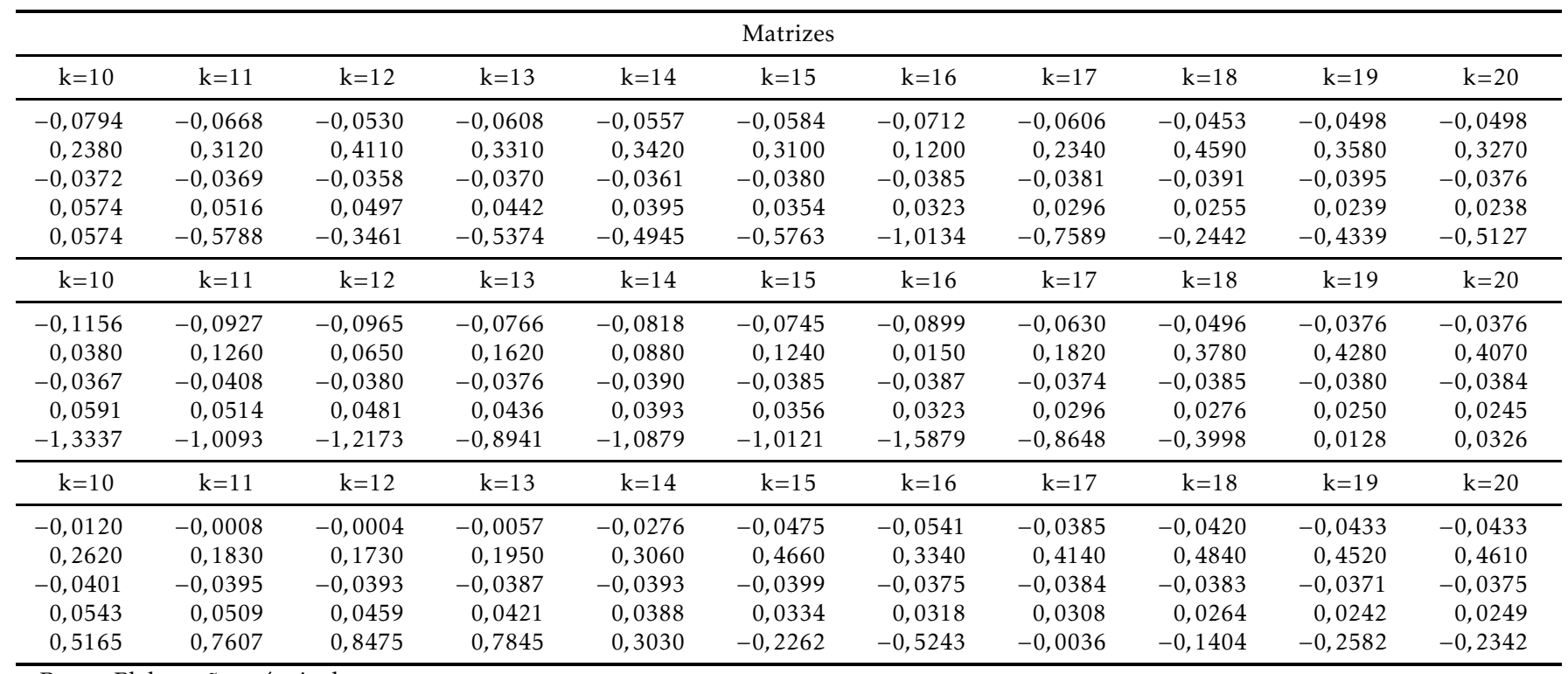


Tabela A.2: Teste de dependência espacial para os resíduos dos modelos cross-section estimados por MQO

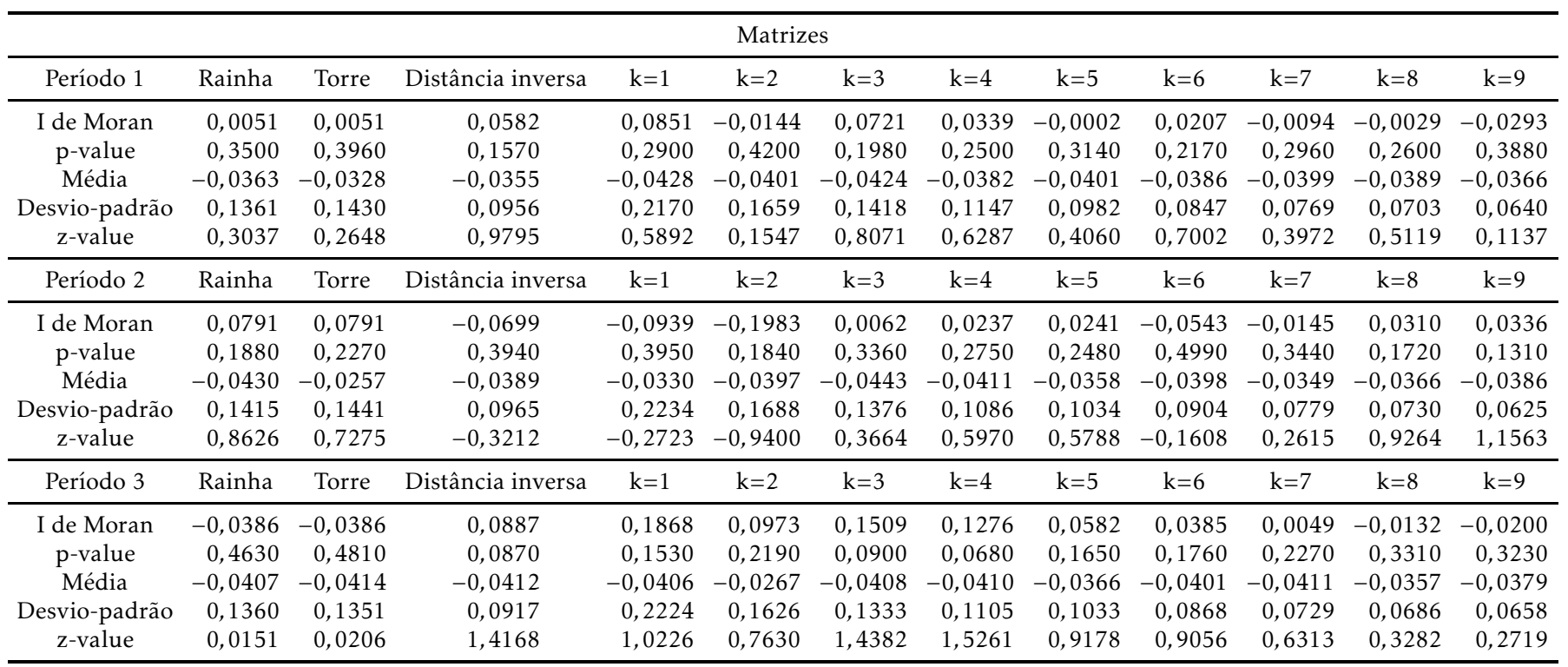

Fonte: Elaboração própria dos autores. 
Tabela A.2: Teste de dependência espacial para os resíduos dos modelos cross-section estimados por MQO (continuação)

\begin{tabular}{rrrrrrrrrrr}
\hline \multicolumn{10}{c}{ Matrizes } \\
\hline $\mathrm{k}=10$ & $\mathrm{k}=11$ & $\mathrm{k}=12$ & $\mathrm{k}=13$ & $\mathrm{k}=14$ & $\mathrm{k}=15$ & $\mathrm{k}=16$ & $\mathrm{k}=17$ & $\mathrm{k}=18$ & $\mathrm{k}=19$ & $\mathrm{k}=20$ \\
\hline$-0,0317$ & $-0,0200$ & $-0,0433$ & $-0,0472$ & $-0,0435$ & $-0,0468$ & $-0,0587$ & $-0,0844$ & $-0,0676$ & $-0,0641$ & $-0,0563$ \\
0,3700 & 0,3140 & 0,4670 & 0,4840 & 0,4760 & 0,4940 & 0,2800 & 0,0170 & 0,1000 & 0,1120 & 0,1590 \\
$-0,0372$ & $-0,0371$ & $-0,0397$ & $-0,0389$ & $-0,0396$ & $-0,0394$ & $-0,0384$ & $-0,0398$ & $-0,0391$ & $-0,0384$ & $-0,0380$ \\
0,0592 & 0,0515 & 0,0461 & 0,0422 & 0,0397 & 0,0352 & 0,0310 & 0,0284 & 0,0268 & 0,0242 & 0,0205 \\
0,0934 & 0,3316 & $-0,0782$ & $-0,1969$ & $-0,0992$ & $-0,2105$ & $-0,6545$ & $-1,5731$ & $-1,0654$ & $-1,0597$ & $-0,8907$ \\
\hline $\mathrm{k}=10$ & $\mathrm{k}=11$ & $\mathrm{k}=12$ & $\mathrm{k}=13$ & $\mathrm{k}=14$ & $\mathrm{k}=15$ & $\mathrm{k}=16$ & $\mathrm{k}=17$ & $\mathrm{k}=18$ & $\mathrm{k}=19$ & $\mathrm{k}=20$ \\
\hline 0,0247 & 0,0267 & $-0,0049$ & $-0,0231$ & $-0,0108$ & 0,0128 & $-0,0084$ & $-0,0313$ & $-0,0109$ & $-0,0109$ & $-0,0159$ \\
0,1250 & 0,1140 & 0,1800 & 0,2830 & 0,2050 & 0,0920 & 0,1620 & 0,3710 & 0,1380 & 0,1160 & 0,1320 \\
$-0,0380$ & $-0,0387$ & $-0,0403$ & $-0,0398$ & $-0,0371$ & $-0,0383$ & $-0,0373$ & $-0,0375$ & $-0,0390$ & $-0,0388$ & $-0,0383$ \\
0,0579 & 0,0543 & 0,0470 & 0,0421 & 0,0413 & 0,0367 & 0,0332 & 0,0299 & 0,0263 & 0,0241 & 0,0204 \\
1,0831 & 1,2057 & 0,7534 & 0,3955 & 0,6365 & 1,3930 & 0,8712 & 0,2046 & 1,0673 & 1,1597 & 1,0987 \\
\hline $\mathrm{k}=10$ & $\mathrm{k}=11$ & $\mathrm{k}=12$ & $\mathrm{k}=13$ & $\mathrm{k}=14$ & $\mathrm{k}=15$ & $\mathrm{k}=16$ & $\mathrm{k}=17$ & $\mathrm{k}=18$ & $\mathrm{k}=19$ & $\mathrm{k}=20$ \\
\hline$-0,0180$ & 0,0003 & $-0,0191$ & $-0,0230$ & $-0,0330$ & $-0,0456$ & $-0,0454$ & $-0,0562$ & $-0,0357$ & $-0,0331$ & $-0,0358$ \\
0,3080 & 0,1770 & 0,2810 & 0,2920 & 0,3760 & 0,4850 & 0,4500 & 0,2880 & 0,3850 & 0,3490 & 0,3880 \\
$-0,0369$ & $-0,0416$ & $-0,0380$ & $-0,0385$ & $-0,0371$ & $-0,0379$ & $-0,0363$ & $-0,0376$ & $-0,0376$ & $-0,0379$ & $-0,0377$ \\
0,0555 & 0,0477 & 0,0473 & 0,0441 & 0,0404 & 0,0375 & 0,0325 & 0,0301 & 0,0275 & 0,0234 & 0,0203 \\
0,3418 & 0,8763 & 0,3995 & 0,3518 & 0,0997 & $-0,2048$ & $-0,2809$ & $-0,6172$ & 0,0690 & 0,2043 & 0,0901 \\
\hline Fonte: Elaborac̃a própria dos autores. & & & & & & & & &
\end{tabular}


Tabela A.3: Estatísticas descritivas das variáveis

\begin{tabular}{lcccc}
\hline Variáveis & Média & Desvio-Padrão & Mínimo & Máximo \\
\hline CRESC & 0,005 & 0,008 & $-0,024$ & 0,024 \\
LPIB & 8,383 & 0,547 & 7,280 & 9,970 \\
FEC & 0,936 & 0,216 & 0,557 & 1,396 \\
EDUC & 5,238 & 1,176 & 2,864 & 8,549 \\
INV & 8,276 & 1,461 & 5,083 & 11,492 \\
GOV & $-1,964$ & 0,353 & $-2,801$ & $-1,074$ \\
\hline
\end{tabular}

Fonte: Elaboração própria dos autores.

Tabela A.4: Matriz de correlação das variáveis

\begin{tabular}{lcrrrrr}
\hline Variáveis & CRESC & LPIB & FEC & EDUC & GOV & INV \\
\hline CRESC & 1 & & & & & \\
LPIB & $-0,2310$ & 1 & & & & \\
FEC & $-0,1544$ & $-0,6083$ & 1 & & & \\
EDUC & $-0,1071$ & 0,8207 & $-0,4050$ & 1 & & \\
GOV & $-0,0175$ & $-0,5687$ & 0,5798 & $-0,1999$ & 1 & \\
INV & $-0,0469$ & 0,4772 & $-0,6727$ & 0,1421 & $-0,8295$ & 1 \\
\hline
\end{tabular}

Fonte: Elaboração própria dos autores. 